\title{
Social Psychological Adaptation: A Case Study of the of Migrant Muslims in Lanzhou City, China
}

\author{
Xiang Gao, Hehe Liao \\ College of Earth \& Environmental Sciences, Lanzhou University, Lanzhou, China \\ Email:xgao@|zu.edu.cn
}

Received 27 July 2016; accepted 22 August 2016; published 25 August 2016

Copyright (C) 2016 by authors and Scientific Research Publishing Inc.

This work is licensed under the Creative Commons Attribution International License (CC BY). http://creativecommons.org/licenses/by/4.0/

(c) (i) Open Access

\begin{abstract}
Based on information from 542 survey samples, the social psychological adaptation of Migrant Muslims in Lanzhou city of China is examined using quantitative methods. The results show that: 1) the social psychological adaptation of Migrant Muslims depends on both individual characteristics and unique religious and cultural traditions inherited within this group. In general, Migrant Muslims both have adapted to urban society in their psychology with a low level of adaptation and showed different degree of adaptation between different connotations of psychological adaptation; 2) their social psychological adaptation has changed with their age: relatively highly educated Migrant Muslims show obvious resistance in their psychological adaptation; the ethnic homogeneity (same religious culture, faith, customs, ethnicity and psychology), can serve to shorten the distance between Migrant Muslims and the native Muslims in Lanzhou city, leading to a sense of urban association and acknowledgement of self identity amongst these Migrant Muslims.
\end{abstract}

\section{Keywords}

Migrant Muslims, Social Psychological Adaptation, Factor Analysis, Step-Wise Regression Analysis, Lanzhou City

\section{Introduction}

Approximately three million Migrant Muslims reside in China [1]. Understanding the social phenomenon and process of migrant Muslim urban adaption is therefore an inter-disciplinary study that involves Ethnology, Demography, Sociology, and Geography. Because of the inclusion of variables such as ethnic-religious culture, ethnic traditional customs, and ethnic psychology during their introduction to urbanization and modernization, 
Migrant Muslim's adaptation to urbanization is often more complex and decorated than usual [2]. This has therefore become a topic of focus for scholars. The psychological adaptation of Migrant Muslims depends on both individual characteristics and unique religious and cultural traditions inherited within this group. The process of urban adaptation usually involves four segments: environment, economics, society, and cultural and social psychology [3]. As the final stage of their urban adaptation, the psychological adaptation is symbolic of the final transition of their identity, role, ethnicity and self-consciousness into city [4] [5]. Most adaptation models fall within two categories, which are "merger into cities through self conversion" and "reconstruction of habitual cultures and environments within the city" [6]. Migrant Muslims possess a strong desire to reconstruct their habitual religious and cultural traditions within the city. R. E. Park [7] believes that "cities have developed their own unique urban psychology, which is very different to the rural psychology". Eventually, like native Muslims, Migrant Muslims not only developed ethnical activity boundaries but also preserved ethnical psychology boundaries. As the unique ethnic group, their understanding of "individuality" and "recognition" and their sense of belonging to cities will determine whether they will experience psychological conflicts and the extent of their "isolation" [8]-[10]. This study defines urban social psychological adaptation into several dimensions including inclination towards future destinations, self acceptance, self identification, and present state perception. Each dimension involves several parameters, and will compare using three-level scale, as an attempt to define and evaluate the status of Migrant Muslim's urban social psychology.

\section{Methodology}

\subsection{Area of Study}

The study area, Lanzhou city, is one of typical large city inhabited by many ethnic groups in Northwest China. As the capital of Gansu Province and transport hub in Northwest China, the city covers approximately 13,085.6 $\mathrm{km}^{2}$ with a census population of 3.83 million in 2010 (Figure 1). It comprises five urban districts (Chengguan, Qilihe, Anning, Xigu, and Honggu) and three counties (Yuzhong, Yongdeng, and Gaolan). Now 37 minorities

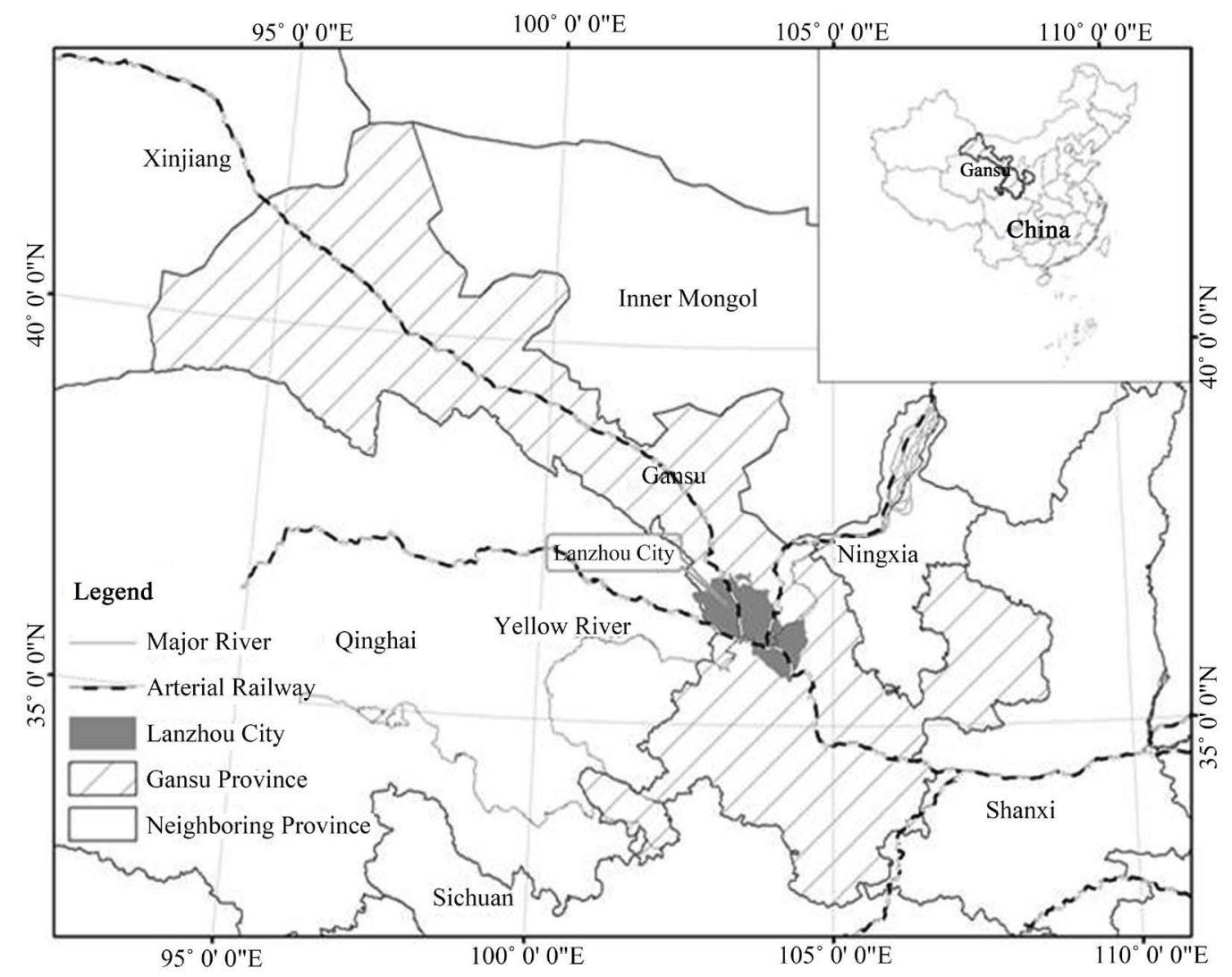

Figure 1. Area of study: Lanzhou city in northwest China. 
reside with a population of 116,200 in 2010, accounting for 3.6\% of the total population in Lanzhou. 10 minorities of them, mainly Hui, Dongxiang, Shala, Baoan, Uygur, and Kazak, profess Islam. These 10 minorities have a population of 110,000 , accounting for $94.7 \%$ of Lanzhou's minority population (Lanzhou's Statistical Bureau 2009). Moreover, approximately 72,000 Migrant Muslims reside in Lanzhou, 54,000 of which are located in the Chengguan, Qilihe, Anning, and Xigu [11].

\subsection{Data Collection}

Historically, Migrant Muslims in Lanzhou are mainly concentrated in several important regions, including Xiaoxihu and Shangxiyuan of Qilihe, Xiguanshizi and Dongbushichang of Chengguan, Peiliguangchang of Anning district and Fulilu of Xigu [12]. Thus, the Migrant Muslims found in these regions were selected for the detailed survey by questionnaire (Figure 2).

On July 2009, 600 questionnaires were sent out and 566 questionnaires were returned, representing an effective recovery rate of $94.3 \%$. In all, 24 questionnaires were eliminated from our analysis due to incomplete information as other problems; thus, 542 questionnaires were finally selected representing an effective percentage of $90.3 \%$.

The questionnaire involved queries on many aspects related to the urban social psychological adaptation of Migrant Muslims in Lanzhou. Beyond the basic information of Migrant Muslims such as gender, age, marital status, educational level, origin etc., there are 40 other items separately belonging to nature environmental, economic, social-cultural and psychological adaption.

\subsection{Multiple Characteristics of Migrant Muslims}

The survey respondents include 325 males and 217 females; $86.5 \%$ of the respondents are married. Of the 542 participants, 76 are aged under 20, 64 are aged $21-30,217$ are aged $31-40,176$ are aged $41-50$, and 9 are aged over 50, most of which fell into the elderly category. In theory the urban social adaptation of Migrant Muslims is closely related to their education, occupation and monthly income besides their gender (Table 1).

First, most of the respondents report receiving only standard education; more females were found to be illiterate than males; the respondents aged 21 - 30 have better educational backgrounds, equivalent to college or higher. Second, most Migrant Muslims were found to either have set up a small business such as retail sale of ethnic food, clothes, and religious products, or work as waiters in restaurants or as part-timers or builders in construction sites. Few work in white-collar jobs as officials. Many Muslim teenagers under 20 work in Muslim-owned restaurants, accounting for $71.1 \%$ of all. Third, the monthly income of all Migrant Muslims was found to be far below that of urban residents in Lanzhou. Of the respondents, $40.2 \%$ reported a monthly income under $1000 \mathrm{CNY}$, making it difficult for them to keep a normal standard of living. Overall, Migrant Muslims in Lanzhou could be characterized as having lower education, less promotion, and less monthly income than the average resident of Lanzhou, which, in some way, determine the pattern of their spatial behavior.

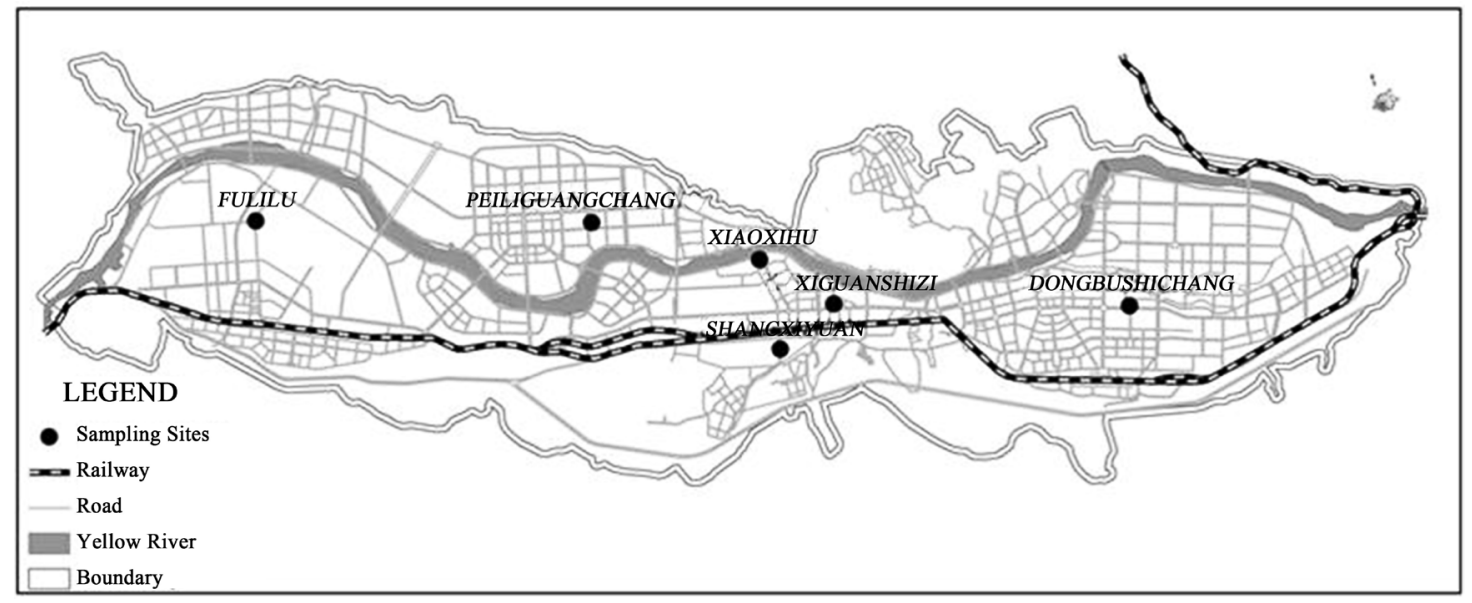

Figure 2. Survey sites in Lanzhou city. 
Table1. Descriptive statistic for survey samples collected in 2010 in Lanzhou ( $=542)$.

\begin{tabular}{|c|c|c|c|c|c|c|c|c|c|c|}
\hline \multirow{3}{*}{ Variable } & \multicolumn{10}{|c|}{ Age, years } \\
\hline & \multicolumn{2}{|c|}{$\leq 20(\mathrm{n}=76)$} & \multicolumn{2}{|c|}{$21-30(n=64)$} & \multicolumn{2}{|c|}{$31-40(n=217)$} & \multicolumn{2}{|c|}{$41-50(n=176)$} & \multicolumn{2}{|c|}{$\geq 50(\mathrm{n}=9)$} \\
\hline & No. & $\%$ & No. & $\%$ & No. & $\%$ & No. & $\%$ & No. & $\%$ \\
\hline \multicolumn{11}{|l|}{ Education } \\
\hline Illiterate & 2 & 2.6 & 0 & 0.0 & 7 & 3.2 & 11 & 6.3 & 8 & 88.9 \\
\hline Primary school & 13 & 17.1 & 12 & 18.8 & 109 & 50.2 & 113 & 64.2 & 1 & 11.1 \\
\hline Secondary school & 55 & 72.4 & 43 & 67.2 & 85 & 39.2 & 41 & 23.3 & 0 & 0.0 \\
\hline Junior college and higher & 6 & 7.9 & 9 & 14.0 & 16 & 7.4 & 11 & 6.3 & 0 & 0.0 \\
\hline \multicolumn{11}{|l|}{ Job } \\
\hline Self-employed & 0 & 0.0 & 1 & 1.6 & 69 & 31.8 & 85 & 48.3 & 9 & 100.0 \\
\hline Builder & 18 & 23.7 & 23 & 35.9 & 78 & 35.9 & 14 & 8.0 & 0 & 0.0 \\
\hline Catering waiter & 54 & 71.1 & 32 & 50.0 & 21 & 9.7 & 17 & 9.7 & 0 & 0.0 \\
\hline Official & 0 & 0.0 & 1 & 1.6 & 13 & 6.0 & 21 & 11.9 & 0 & 0.0 \\
\hline Part-time job & 4 & 5.2 & 7 & 10.9 & 36 & 16.6 & 39 & 22.1 & 0 & 0.0 \\
\hline \multicolumn{11}{|l|}{ Monthly income (CNY) } \\
\hline$\leq 500$ & 5 & 6.6 & 1 & 1.6 & 9 & 4.1 & 0 & 0.0 & 0 & 0.0 \\
\hline $500-2000$ & 71 & 93.4 & 60 & 93.7 & 187 & 86.2 & 167 & 94.9 & 9 & 100.0 \\
\hline $2000-5000$ & 0 & 0.0 & 3 & 4.7 & 21 & 9.7 & 9 & 5.1 & 0 & 0.0 \\
\hline$\geq 5000$ & 0 & 0.0 & 0 & 0.0 & 0 & 0.0 & 0 & 0.0 & 0 & 0.0 \\
\hline
\end{tabular}

\subsection{Methods}

\subsubsection{Factor Analysis}

A statistical analysis based on the study of the relationship between internal variables and the categorization of complex variables into a few factors. Basically, we aim to categorize observed variables; highly related variables will be classed into the same factor, so that factor represents a basic structure or public factor. This study aims to use a combination of the linear function of few, unpredictable public factors and unique factors to describe each component of the original observation. Factor analysis has two core problems: constructing factor variables, and identifying and characterizing factor variables [13].

\subsubsection{Stepwise Regression Analysis}

Refers to the process of using compact inverse transformation method and two-test method to study and establish optimum regression equation during variable regression analysis. This will be applied to the variable linear regression analysis of geographic analysis and decision making. The best equation refers to the regression equation that includes all the variables that are strongly influenced by variable $\mathrm{Y}$ and excludes all variables that are insensitive to variable Y. Stepwise regression analysis imports or excludes variables based on the magnitude of their response to $\mathrm{Y}[14]$.

\section{Results and Discussion}

\subsection{Urban Social Psychology Adaptation of Migrant Muslims}

This investigation revealed several urban social psychology adaptation parameters of Migrant Muslims (Table 2) that are correlated, resulting in some data overlap and thus hindering effective analysis. It is necessary to simplify 
Table 2. Three-level scale of urban psychological adaptation.

\begin{tabular}{|c|c|c|c|}
\hline \multirow{2}{*}{ Parameter } & \multicolumn{3}{|c|}{ Percentile (\%) } \\
\hline & Match & Unclear & Not matching \\
\hline 1. Care about how others treat oneself & 62.9 & 26.2 & 10.9 \\
\hline 2. Concerned for and actively motivates others & 77.4 & 20.3 & 2.3 \\
\hline 3. Readily approachable & 60.0 & 34.7 & 5.3 \\
\hline 4. No one to talk to about personal issues & 31.7 & 27.5 & 40.8 \\
\hline 5. Had avoided social interaction & 24.1 & 27.9 & 48.0 \\
\hline 6. Often feels fear, stressed, worried & 23.8 & 20.3 & 55.9 \\
\hline 7. Often bullied & 15.0 & 15.3 & 69.7 \\
\hline 8. Confident about future & 72.4 & 24.4 & 3.2 \\
\hline 9. Believes oneself to be worthy & 65.9 & 30.9 & 3.2 \\
\hline 10. Belongs to urban population & 43.2 & 21.2 & 35.6 \\
\hline 11. Feels the city people to have prejudice against migrant workers & 31.2 & 41.2 & 27.6 \\
\hline
\end{tabular}

the data and preserve only the most representative and epitomized parameters. Therefore, SPSS 17.0 was used to carry out factor analysis on each parameter based on the statistics described in Table 2.

Parameters 4 - 7 and 11 had opposite scoring orientation to the whole scale, and therefore positive scoring needs to be applied (scoring scheme: "match" score +1 points, "unclear" score 0 points, "not matching" score -1 points). All 11 factors will then be evaluated using the KMO (Kaiser-Meyer-Olkin) test, for which the consensus is that if the result of the test falls below a value of 0.5 , then the factors are not suitable for analysis. The 11 factors tested had a KMO score of 0.726 , Bartlett test of sphericity chi-square value of 345.200 , degree of freedom value of 55 and significant on a horizontal distribution of 0.000 . As such, these 11 factors were suitable for analysis.

Kaiser standardized Feels the urban population to have prejudice against other populations positive rotation was applied to the principal components extracted from the factors. Principal components with an eigenvalue greater than 1 were selected as factors for research (Table 3). The 11 parameters were categorized into three factors, which are named "sense of urban belongs", "identity determination" and "self acknowledgement".

The composite score for urban social psychological adaption was obtained using the factor score, calculated using the factor score coefficient for each parameter as standard, and each factor's variance contribution as standard (Table 4).

Each parameter has a score range of $[-1,+1]$, therefore theoretically the factor score of each parameter will have a maximum score of +1 , minimum score of -1 . Because the three public factors combined have a total of 11 parameters, the theoretical factor score range and the theoretical composite score for urban social psychological adaptation will both be $[-11,+11]$. A composite score in the positive range indicates good social psychological adaptation, with positive correlation between score and degree of adaptation. The cross-over value "0" indicates the transition of urban social psychological adaptation status from adapted to unfit.

From Table 5, Migrant Muslims had an urban social psychological adaptation composite score range of $[-0.243,+0.593]$, and mean value of 0.228 . This suggests that Migrant Muslims have generally adapted to urban society, although the small mean signifies a low level of adaptation. An analysis of the actual composite scores of each migrant Muslim individual showed that: 68 individual scored less than 0; 3 individuals scored exactly 0; and the majority, 471 individuals, scored greater than 0 ( $86.8 \%$ of total respondents).

From the factors analyzed the "self acknowledgement" factor had the smallest mean, suggesting that as far as "acknowledgement" is concerned, Migrant Muslims is not adapted in terms of "urban acknowledgement", "social acknowledgement", and "identity acknowledgement"; they realize the difference between them and urban citizens and are unable to "really" integrate into social life outside of their own ethnic group. In terms of "sense of urban belongs", because of their strong "temporary employment" and "passing by" mentality, they see Lanzhou city as "theirs" not "ours" and feel that their "roots" are still in their homeland. With regards to "identity determination", Migrant Muslims scored a relatively high mean score of 0.68791 , suggesting that they acknowledge themselves as urban citizens, though without strong desire. 
Table 3. Summary of urban social psychological adaptation factor.

\begin{tabular}{|c|c|c|c|}
\hline \multirow{2}{*}{ Parameters } & \multicolumn{3}{|c|}{ Extraction factors } \\
\hline & Factor $_{1}$ & Factor $_{2}$ & Factor $_{3}$ \\
\hline 1. Care about how others treat oneself & - & - & 0.605 \\
\hline 2. Concerned for and actively motivates others & - & - & 0.629 \\
\hline 3. Readily approachable & - & - & 0.516 \\
\hline 4. No one to talk to about personal issues & 0.538 & - & - \\
\hline 5. Had avoided social interaction & 0.711 & - & - \\
\hline 6. Often feels fear, stressed, worried & 0.788 & - & - \\
\hline 7. Often bullied & 0.551 & - & - \\
\hline 8. Feels the city people to have prejudice against migrant workers & 0.587 & - & - \\
\hline 9. Confident about future & - & 0.542 & - \\
\hline 10. Believes oneself to be worthy & - & 0.711 & - \\
\hline 11. Belongs to urban population & - & 0.732 & - \\
\hline New factors' name & Sense of urban belongs & Identity determination & Self acknowledgement \\
\hline Eigenvalue & 2.192 & 1.603 & 1.192 \\
\hline Calculation variance contribution rate & 19.925 & 14.574 & 10.833 \\
\hline Cumulative variance contribution rate & 19.925 & 34.499 & 45.332 \\
\hline
\end{tabular}

Table 4. Factor score coefficient matrix.

\begin{tabular}{lccc}
\hline \multicolumn{1}{c}{ Parameters } & \multicolumn{2}{c}{ Extraction factors } \\
\cline { 2 - 4 } & \multicolumn{1}{c}{ Sense of urban belongs } & Identity determination & Self acknowledgement \\
\hline 1. Care about how others treat oneself & -0.032 & -0.166 & 0.456 \\
2. Concerned for and actively motivates others & -0.018 & 0.095 & 0.425 \\
3. Readily approachable & 0.075 & 0.025 & 0.355 \\
4. No one to talk to about personal issues & 0.252 & 0.095 & -0.041 \\
5. Had avoided social interaction & 0.359 & 0.001 & -0.080 \\
6. Often feels fear, stressed, worried & 0.403 & -0.067 & 0.246 \\
7. Often bullied & 0.297 & -0.215 & 0.169 \\
8. Confident about future & -0.058 & 0.333 & 0.037 \\
9. Believes oneself to be worthy & -0.021 & 0.457 & -0.244 \\
10. Belongs to urban population & -0.015 & 0.518 & 0.096 \\
11. Feels the city people to have prejudice against migrant workers & 0.237 & 0.013 & \\
\hline
\end{tabular}

Table 5. Descriptive statistics of urban social psychological adaptation factor score.

\begin{tabular}{lcccccc} 
& $\mathrm{N}$ & Minimum & Maximum & Mean & Standard deviation & Variance \\
\hline Self acknowledgement & 542 & -1.486 & 1.659 & 0.40656 & 0.778812 \\
Urban sense of belongs & 542 & -1.406 & 1.851 & 0.49765 & 0.554388 \\
Identity determination & 542 & -1.515 & 1.867 & 0.68791 & 0.588031 \\
Urban psychological adaptation & 542 & -0.243 & 0.593 & 0.228 & 0.346 \\
\hline
\end{tabular}




\subsection{Key Factors Affecting Migrant Muslims Urban Social Psychological Adaptation}

We used stepwise analysis to determine key factors affecting Migrant Muslims urban social psychological adaptation. The main independent variables are individual variables $\left(\mathrm{X}_{1}\right)$ including Migrant Muslim's sex, age, marital status and education level, economic variables $\left(\mathrm{X}_{2}\right)$ including monthly family income and occupation, and socio-cultural variables $\left(\mathrm{X}_{3}\right)$ including "befriending people with different faith" and "understanding ethnic cultural traditions". We treated these three variables in order with three step regression analysis and arrived at a value with an acceptable goodness of fit (Table 6).

The $\mathrm{R}^{2}$ values of self acknowledgement, urban attribution, and identity acknowledgement were $0.085,0.088$, and 0.016 respectively. The reduction errors of the three equations were all below $10 \%$, suggesting a poor goodness of fit with the model. The $\mathrm{R}^{2}$ value of urban social psychological adaptation was 0.133 , observed value of $\mathrm{F}$ statistic was 16.989 , probability value of $\rho 0.000$, suggesting significance at the 0.05 significance value, indicating a good fit with the model. In general, the three factors that were most influential to Migrant Muslims urban social psychological adaptation are: family monthly income (0.116), education level (0.032), and age (0.004). The effects of each factor are as follows.

\subsubsection{Difference in "Age" of Migrant Muslim Accounts for Fluctuations in Level of Psychological Adaptation}

The Migrant Muslims in this study ranged between 15 years to 60 years of age, with a mean age of 35 years, medium age of 38 years, and two population peaks by age (Figure 3 ).

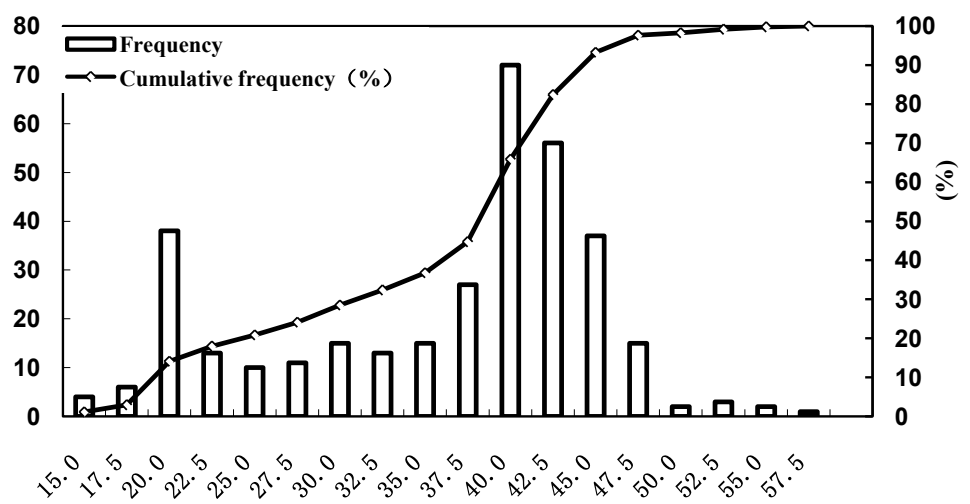

Age (years)

Figure 3. Age structure of Migrant Muslims.

Table 6. Results of stepwise regression analysis on key factors affecting urban social psychological adaptation.

\begin{tabular}{|c|c|c|c|c|}
\hline Variable & Self acknowledgement & Urban sense of belongs & Identity determination & $\begin{array}{c}\text { Urban social psychological } \\
\text { adaptation }\end{array}$ \\
\hline Sex & - & - & - & - \\
\hline Age & $0.017^{* * *}$ & $0.008^{* *}$ & - & $0.004^{* * *}$ \\
\hline Marital status & - & - & - & - \\
\hline Educational level & - & $0.120^{* * *}$ & - & $0.032^{* * *}$ \\
\hline Occupation & - & - & - & - \\
\hline Monthly family income & $0.421^{* * *}$ & - & - & $0.116^{* * *}$ \\
\hline $\begin{array}{l}\text { Befriending people } \\
\text { with different faith }\end{array}$ & - & $0.115^{* *}$ & $0.125^{*}$ & - \\
\hline $\begin{array}{l}\text { Understanding ethnic } \\
\text { cultural traditions }\end{array}$ & - & - & - & - \\
\hline $\mathrm{R}^{2}$ & 0.082 & 0.088 & 0.016 & 0.133 \\
\hline $\mathrm{F}$ & $15.124^{* * *}$ & $10.771^{* * *}$ & $4.447^{*}$ & $16.989^{* * *}$ \\
\hline
\end{tabular}

Note: $\mathrm{P}<0.10 ;{ }^{*} \mathrm{P}<0.05 ;{ }^{* *} \mathrm{P}<0.01 ;{ }^{* * *} \mathrm{P}<0.001$; Beta coefficients that were not significant following statistical analysis were not listed. 
The first peak represents teenagers around 20 years old, who work mainly in catering services and construction, and have on average junior high level of education. The second peak represents married mid-aged individuals around 40 years, who are mainly self-employed and mostly have junior to junior high level of education. There is an underlying meaning that accounts for the appearance of the two peaks. Migrant Muslims of Lanzhou city mainly come from the Lanxia Hui autonomous prefecture and the Tianshui Zhangjiachuan autonomous county, two relatively remote, economically behind, and environmentally poor ethnical areas [15]. Muslims have long formed a deep commercialization instinct, and doing business had become a tradition in many families. In addition, increasing graduate employment pressure and unequal allocation of education resources have led to the spread of the "new education is useless argument" amongst the western areas of the Muslim settlements. This resulted in many Muslims leaving school for work, the majority of which are teenagers around 20 years old. At the same time, the continued downturn and slack of agricultural income and increasing family burdens incentivize many 40 year old family-providers to move to the city in search of better paid jobs to support their family.

The plot in Figure 4 shows the relationship of the composite score of urban adaptation of Migrant Muslims as a function of Migrant Muslims age groups. Migrant Muslims in the age group 20 - 30 years displayed poor social psychological adaptation levels, which improves with the $30-50$ age group, but decreases again for 50 years and older.

The reasons that the 20 - 30 age groups had low levels of urban social psychological adaption was because this population lacked many skills and social experience, are undertaking unstable and low paid jobs, and some have marriage and parental support pressures, resulting in low levels of urban attribution and identity confusion. In contrast, people within the 30 - 50 age groups had more social experience, a certain level of skills and economic savings, a comparatively better "fitting into society" foundation, and stronger psychological endurance. The 50 and beyond age groups, however, are mostly suffering from physical problems, lack of competitive edge, strong "homeward" mentality, and poor urban attribution, resulting in poor social psychological adaptation.

\subsubsection{Education Level Has a Positive Contribution to Social Psychological Adaptation}

Identity characteristics determine the depth and magnitude of merging between multi-cultural groups and local society, and their different cultural psychological acknowledgement and adaptation model. As an important identity characteristic, education level plays a hugely influential role in the urban cultural psychological adaptation of individuals. As they enter the cities, Migrant Muslims will try to understand and identify the main different cultures they come across. Their level of understanding will strongly depend upon their level of education. In general, the more similar the structures of two different cultures are, the easier it is for them to identify and accept each other. This survey of the literacy level of the Lanzhou city Migrant Muslims showed: They are mostly educated at junior and junior high levels, contributing to $26.5 \%$ and $40.9 \%$ of the total respondents respectively.

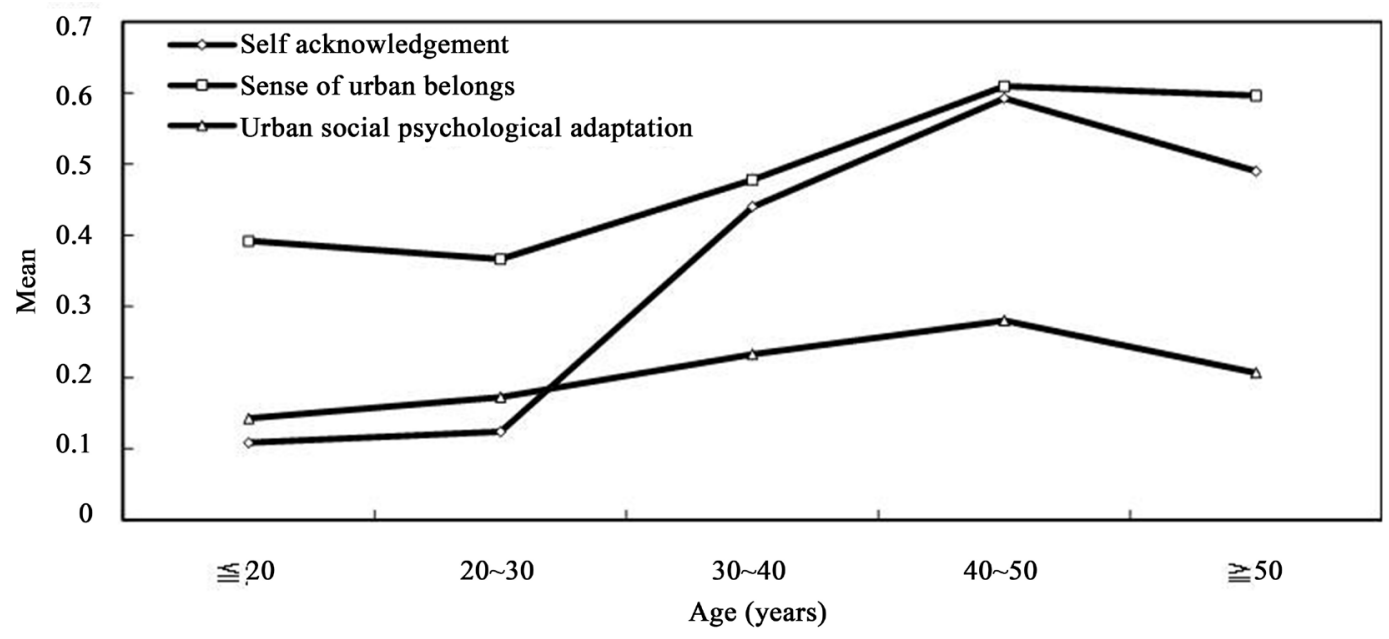

Figure 4. Trend in change in urban adaptation with age. 
Generally low education level is a key determinant for the overall low levels of urban social psychological adaptation. At the same time, "literacy level" has a significant promotional effect for urban association and urban social psychological adaptation; higher literacy levels correspond to higher survival capabilities, more significant urban association, and better urban social psychological adaptation (Figure 5). In particular, in terms of employment psychological adaptation, people with higher literacy levels will have stronger preferences and independence in their job selection.

However, the relationship between Migrant Muslim literacy level and their urban social psychological adaptation is not a simple proportional promotion, but rather a complicated decision process. Due to historical reasons, Muslim education is composed of both religious education and national education. As Ding Ming Jun [16] has identified: Historically Muslim communities are concerned about "more reading gives less religion". The education system of China's feudal society, which has a tendency to harmonize different cultures, has also led the Muslim communities to develop an anti-Han culture psychology. In order to survive in the city, Migrant Muslims are forced to interact with people from different cultural backgrounds, to try different jobs, and to acquire different skills. Therefore, the diversity of the urban society and culture will inevitably have some impact and influence on the values and outlook of Migrant Muslims.

In fact, highly educated Migrant Muslims are willing to accept and integrate mainstream and suitable urban culture and customs, and are willing to try different things so that they may be accepted by the city. At the same time, they preserve strong ethnic awareness and values, becoming strong upholders of ethnic culture and customs in their tribes. Their urban social psychological adaptation is developed amongst much struggle and conflict.

\subsubsection{Family Income Has a Significant Influence on Urban Social Psychological Adaptation}

According to survey, the majority of Migrant Muslims of Lanzhou city has a family income either between 500 $1000 \mathrm{CNY}$ or between $1000-2000 \mathrm{CNY}$, corresponding to $43.8 \%$ and $25.6 \%$ of the total respondents respectively. Using multiple step-wise regression analysis we identified a positive correlation between family income level and Migrant Muslim urban adaptation (Figure 6); the higher the family income the better the urban psychological adaptation ability, and vice verse. The fact that Migrant Muslims on average have a low family income has, to a great extent, determined the low levels of their social psychological adaptation.

According to a survey published on 10th Oct, 2006, by the national bureau of statistics on the urban living conditions of migrant workers: Urban migrant workers have, on average, low salaries, poor quality of life, unguaranteed housing and medical conditions, monotonous leisure, generally low labor skills, and prominent offspring education problems. Migrant Muslims of Lanzhou city experience urban living conditions similar to that described above, and in fact, have worse housing and offspring education problems than that described in the survey above. Economic adaption is the foundation and prerequisite for all other forms of adaptation; only

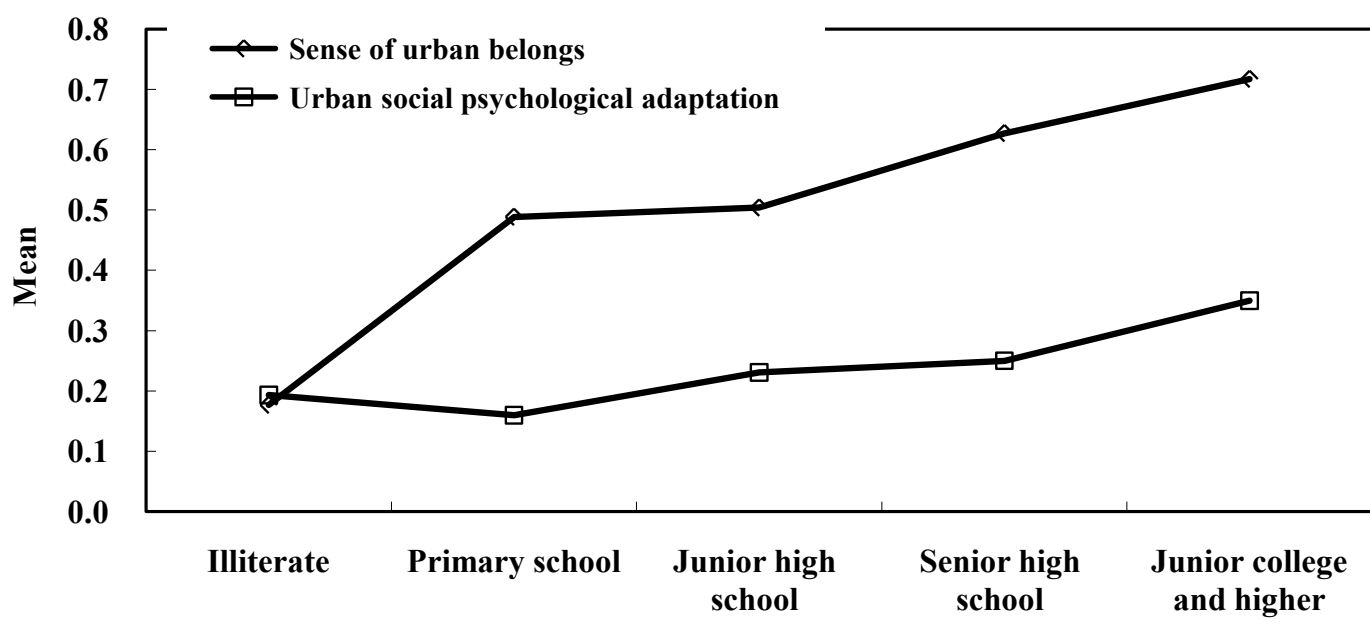

Level of education 


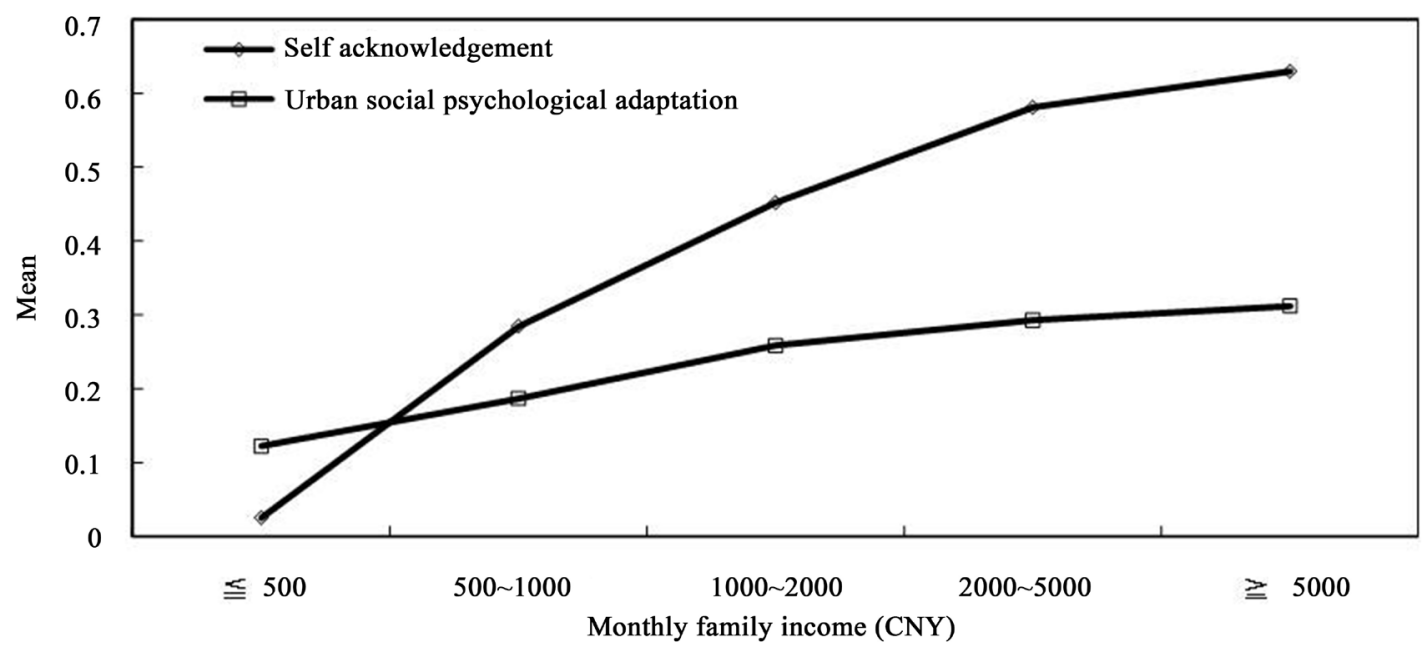

Figure 6. Effect of family income on level of urban social psychological adaptation.

when economically one can satisfy basic survival necessities can one then try to interact with the society and enjoy cultural entertainment. Because of the influence of religious culture and dietary customs, the employment criteria of Migrant Muslims are mostly restricted to sectors or industries that are related to ethnic economy. The low employment opportunities lead to unguaranteed income, and the persistent down period leads to psychological confusion and helplessness. This leads to the development of a social group prone to have social problems such as theft, robbery, drug trafficking, and trouble making. Without an economic foundation suitable for urban survival, the feeling of "marginal citizen" cannot be erased and therefore leaves no room for social psychological adaptation.

\subsubsection{Ethnicity Has Deep Influences on Social Psychological Adaptation}

Although "interaction with people holding different faiths" is not a significant factor influencing urban social adaption, it still dramatically influences the "sense of urban belongs" and "identity determination" related to Migrant Muslim urban social adaptation. Understanding these two factors is related to whether Migrant Muslims experience psychological conflict and the level of their marginality. This shows that Migrant Muslims differ significantly from other non-faith ethnics, such as the majority Han migrant population, in terms of urban social adaptation; ethnicity deeply influences the Migrant Muslim urban social psychological adaptation level and procedure.

Migrant Muslims adapt to city life based on the mutual cultural and ethnicity acknowledgement. According to Geertz [17], religion, as a symbol of the basic qualities of culture, forms the crux of culture, and is symbolic of an ethnic ethos-life styles, characteristics, and quality. Although urban Muslims still, to a large extent, dwell and work in the surrounding areas of the mosque, the level of dispersion has increased in recent years [15]. Following the diverse development of urban economics and culture, and following the increased scope of activities of Migrant Muslims, there will inevitably be more frequent contacts and mutual influences between Muslim and non-Muslim cultures. Migrant Muslims are in a dilemma when trying to improve their urban living conditions but at the same time, strongly uphold their ethnic cultural customs and faith.

According to Everett S. Lee [18], of the factors determining migration, psychological distance is by far more important than geographical difference. As Chinese Sociologist Ma Rong [19] pointed out, "Population migration tends to be towards a location where there is a highly populated settlement of people with the same ethnic background, so as to have the benefits of same language and customs, and a strong cultural association. Following migration small settlements of people of the same ethnicity will spontaneously develop, so that the ethnic and religious customs can be preserved, help in general is readily available, and easier for the group to claim for their legitimate rights". According to the survey, Lanzhou Migrant Muslims have a high level of urban association and identity determination, mainly because Lanzhou city is highly populated by Muslims and has many Islamic areas. For example, the city has 83 mosques and qubbas [12]. Therefore ethnic homogeneity (same religious culture, faith, customs, ethnicity and psychology), plus help within the community, serves to shorten the 
distance between Migrant Muslims and the native Muslims in Lanzhou city, leading to a sense of urban association and acknowledgement of self identity amongst these Migrant Muslims.

\section{Conclusions}

In general, Migrant Muslims in Lanzhou city of China both have adapted to urban society in their psychology with a low level of adaptation and showed different degree of adaptation between different connotations of psychological adaptation. As far as "acknowledgement" is concerned, Migrant Muslims are not adapted in terms of "urban acknowledgement", "social acknowledgement" and "identity acknowledgement". Migrant Muslims realize the difference between them and urban citizens and are unable to "really" integrate into social life outside of their own ethnic group. In terms of "sense of urban belongs", because of their strong "temporary employment" and "passing by" mentality, Migrant Muslims see Lanzhou city as "theirs" not "ours" and feel that their "roots" are still in their homeland. With regards to "identity determination", Migrant Muslims acknowledge themselves as urban citizens, though without strong desire.

Social psychological adaptation of Migrant Muslims changed with their age, literacy, occupation and monthly income. Difference in "age" of Migrant Muslim accounted for fluctuations in level of psychological adaptation, and Migrant Muslims in the age group 30 - 50 years displayed good social psychological adaptation. Though education level has a positive contribution to social psychological adaptation, the relationship between Migrant Muslim literacy level and their urban social psychological adaptation is not a simple proportional promotion, and some highly educated Migrant Muslims show obvious resistance in their urban social psychological adaptation. Moreover, the ethnic homogeneity (same religious culture, faith, customs, ethnicity and psychology), plus help within the community, serves to shorten the distance between Migrant Muslims and the native Muslims in Lanzhou city, leading to a sense of urban association and acknowledgement of self identity amongst these Migrant Muslims.

\section{Acknowledgements}

The work described in this paper was supported by the National Social Science Foundation of China (Grant No. 14BSH027).

\section{References}

[1] Qiu, Y.H. (2014) Annual Report on Religions in China. Social Sciences Academic Press, Beijing, 1-35.

[2] Hao, S.Y. (2014) Growth of Major Powers and the Ethnic Issue: China's Case and the Global Scenario. International Economic Review, 5, 9-34.

[3] Gao, X., Cheng, H.B. and Yu, T.F. (2010) Adaptation to City for Migrant Muslims in Lanzhou City. Chinese Journal of Population Science, 1, 101-110.

[4] Bai, Y.T. and Chen, B.C. (2007) Migrant Muslims and the Hui Communities in Large City. Journal of Hui Muslim Minority Studies, 4, 21-32.

[5] Cai, Y. (1995) Population Migration and Its Cause, Trend and Policy. Chinese Journal of Population Science, 6, 8-16.

[6] Wang, L.H. (2003) Urbaniam and Urban Adaptation of the Migrant Workers. Social Science Research, 5, 92-96.

[7] Park, R.E. (1987) Urban Sociology. Songjunling Translation, Huaxia Press, Beijing, 23-29.

[8] Geertz, C. (1999) Cultural Interpretation. Shanghai People Publishing House, Shanghai, 103.

[9] Glandeny, D.C. (1996) Muslim Chinese: Ethnic Nationalism in the People's Republic. Council East Asian Studies, 6, 44-51.

[10] Fei, X.T. (1988) FEi Xiaotong Athology. Tianjin People's Press, Tianjin.

[11] Editorial Board of Statistical Yearbook of Gansu (2008) Statistical Yearbook of Gansu. China Statistics Press, Beijing.

[12] Tang, D.X. (2006) An Analysis of the Characteristics of Ethnic Floating Population in Big Cities of Northwestern China: An Example of Lanzhou City. Ethno-National Studies, 1, 31-40.

[13] Li, R.B. and Zhang, L.Y. (2012) A Study of Floating Population Self-Identity Present Situation and Its Influence Factor: Based on the Survey Data of 106 Cities in Our country. Population \& Economics, 4, 78-86.

[14] Tan, S.H., et al. (2015) A Study on the Urban Consumption of the Floating Population's Families and Its Determinants: Evidence from the National Floating Population's Dynamic Monitoring Survey. Population and Development, 1, $22-31$. 
[15] Gao, X., et al. (2010) Spatial Behavior and Its Driving Mechanism of the Minority Migrations: A Case Study of the Hui and Dongxiang Ethnic Groups, Lanzhou City. Progress in Geography, 6, 716-724.

[16] Ding, M.J. (2004) Study on the Marginal Chinese Muslim. Researches on the Hui, 4, 38-47.

[17] Geertz, C. (1999) The Interpretation of the Culture. Shanghai Population Press, Shanghai, 105.

[18] Lee, E.S. (1966) A Theory of Migration. Demography, 2, 47-57. http://dx.doi.org/10.2307/2060063

[19] Ma, R. (2004) Ethnic Sociology-Study on Ethnic Groups Relationship. Peking University Press, Beijing, 338-345.

\section{Submit or recommend next manuscript to SCIRP and we will provide best service for you:}

Accepting pre-submission inquiries through Email, Facebook, LinkedIn, Twitter, etc.

A wide selection of journals (inclusive of 9 subjects, more than 200 journals)

Providing 24-hour high-quality service

User-friendly online submission system

Fair and swift peer-review system

Efficient typesetting and proofreading procedure

Display of the result of downloads and visits, as well as the number of cited articles

Maximum dissemination of your research work

Submit your manuscript at: http://papersubmission.scirp.org/ 